\title{
Components of functional information model of city environment reorganization in interactive mode
}

\author{
Olga Kuzina ${ }^{1, *}$ \\ ${ }^{1}$ Moscow State University of Civil Engineering, 129337 Yaroslavskoe shosse 26, Moscow, Russia
}

\begin{abstract}
The article contents the description of reorganization complementary information model provided for the lifecycle stage of facility management. The main components or assets of that model are functional, constructive, and organization-technological level of a declination from the project perfect model. There are also three-level model of building reorganization type definition. It represents an operation-automated algorithm for updating the technical specification of building reorganization.
\end{abstract}

\section{Introduction}

The main purpose of building reorganization (BR) is to bring the object to the state, to meet customer requirements by architectural, functional and planning transformation. That is important to understand that the nature of buildings and structures reconstruction is determined not only economic and functional expediency, historical, architectural and environmental restrictions, but also dependent on funds and customer preference [1]. The main tool for improving the efficiency of the organization processes of building reorganization is process of modelling at the planning stage of lifecycle.

Creating a functional model of BR, you can create operation description of system data and analyse the reality of upcoming improvements, changes, range of the necessary expenses of all types of resources, as well as the most well-coordinated work of the subsystems.

This approach will create basis for calculating the cost of reconstruction, creating a base for the project of construction organization (PCO), a technological project of works (TPW), schedules. Analysis shows the opportunity of decision-making on the feasibility of the project and determine its results. The customer has the choice of solutions not only upon the estimated cost, but also after evaluation of time and labour efforts [2].

\section{Functional system of city reorganization}

Functional system of city reorganization designed to provide:

*Corresponding author: kuzinaon@mgsu.ru 
- eliminate physical deterioration or obsolescence,

- changes in the functional purpose,

- increase production capacity,

- equipment replacement,

- restoration of artistic monuments, etc.

Includes:

- designing, engineering,

- production of special materials, structures and equipment,

- development of special technologies, often in the continued operation of the facility [3].

Components of city environment reorganization functional system need to define type of reorganization for completing technical requirements and project of reconstruction organization. These components divided into three levels: functional need, structure damage, organizational and technological production process.

A key point of using building information modelling (BIM) during reorganization stage of life cycle is a principle of the collecting data and documents about all the resources and solutions used in the project. Following this methodology, the reconstruction process remains available for analysis and then for reasonable changes. Using BIM technology in general has important advantages: custom geometric modeling, administration and arrangement of layers, etc.

A significant number of objects in the system are project-oriented, with the possible use of the advantages of their parameterization, so that with small changes they can be reused in similar projects of reconstruction of historical objects. Currently, most libraries of objects with historical simulations are created for the purpose of the one project. It is necessary to expand the existing modelling technology to the modern level of technologies and an even higher level of realism [4-15].

\section{Methodology of determining the type of organizational model}

Functional modeling of BR help to identify the types of features of the facility and presenting them in the form of complementary information model that reflects the process of selecting the right kind of building reorganization. To define the functional operation for BR the manager should use three components of applied three-level model.

Each level represents a set of features: functional need for the reconstruction of buildings (system) or the individual element of the system, physical obsolescence of the specific system element, the elements of the organizational and technological production process as the third defining characteristic, which is determined depending on the structural and functional one. In addition, the third features is express in the organizational technological solution for the production of works on BR site.

For each level designed the database with a set of possible properties. That database is open and expect to be enhance if it will have reasonable proofs.

Presented in Figure 1, a three-level model for determining the type of BR. The first level - the purpose of BR, a functional necessity. It consists of thirteen items regulated by existing regulatory documents.

The second level is a list of structural elements of buildings and structures of the system, consisting of 23 items. The third level - a list of organizational and technological production processes of $\mathrm{BR}$ depending on the functional requirements and structure elements of urban infrastructure system. 
The third feature contains 93 items. It is important to note that these sets are open. After analyzing the three-level features, we can conclude what kind of reorganization is required on site.

Figure 1 also shows the correlation of BR structure with the standards of reorganizational types, regulated by the current regulations, and divided into separate species by researchers of higher education.

There are 8 standard information models (repair, reconstruction, restoration, renovation, recombination, reversation, retrivation, rehabilitation engineering (sanitation)). Each standard model has its information model, as a set of parameters on three grounds - the levels of the structure in Figure 1.The standard is a three-level model with a set of elements on three functional levels.

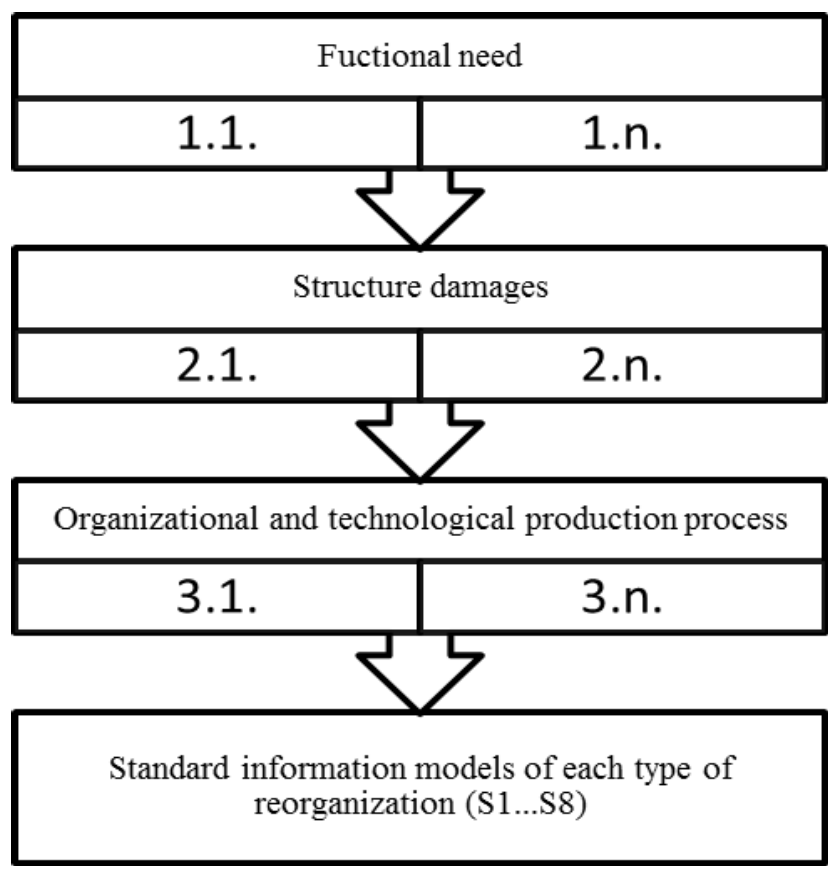

Fig. 1. Three-evel model for determining the type of BR.

\section{Resulting modelling}

Assessment of the BR of non-productive (city urban) sphere objects shows that there is a problem of varieties interpretations multiplicity of BR type, no uniform evaluation criteria, which can be classify as types of restructuring.

It reveals that modern business processes, innovative technologies in the production of construction materials and others define new types of BR, as they have special properties that allow them to identify as an independent kind of reorganization.

It is obvious that for calculating the value of certain types of work there is a need for the designation of operational sets, applying the current needs and innovative processes.

The basis of this choice is a method of dynamic programming, based on the principle of optimality, which can be formulated as follows: to get the best solution, it is necessary to follow the rule - whatever the way to achieve the test system of a state, subsequent decisions must belong to the optimal strategy for the remainder of the path, starting from this condition. 
There are dynamic recurrence:

$$
f_{n}(s)=\min \left[c_{s j}+f_{n-1}(f)\right], n=1,2, \ldots . .
$$

where $f_{n}(s)$ - cost, corresponding to the lowest cost strategy for the path from state $\mathrm{s}$ to the final state of the system, if the rest of the way consists of $\boldsymbol{n}$ steps;

$j_{n}(S)$ - solution to achieve $f_{n}(s)$;

$c_{s j}$ - cost of translation system from the state s to the state $\mathrm{j}$.

So, for the needs of BR, was complete the database including information of three basic levels: functional, organizational, and technological. The purpose of the perfect information model of building reorganization is to automate the processes of completing the documents for providing works of reconstruction or another type of reorganization (Figure 2). That approach would let to evaluate the expenses of money, labor, and time for reorganization processes at the stage of preoperating [3].

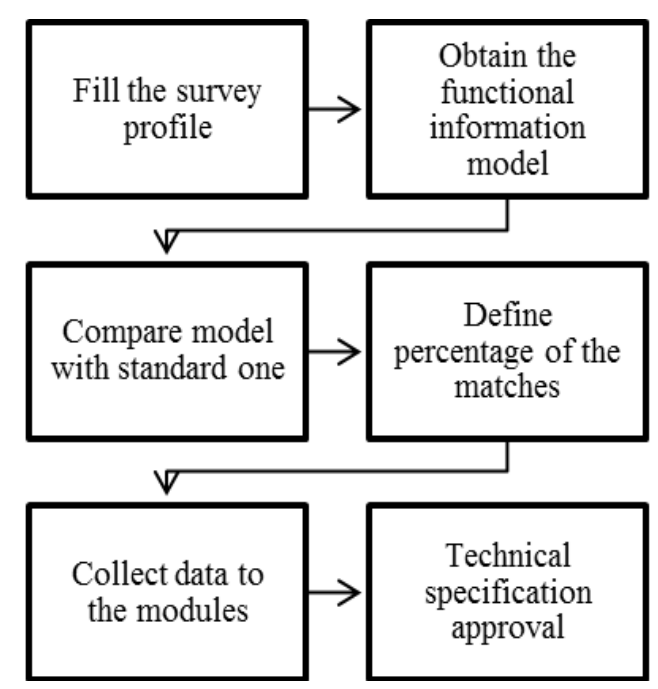

Fig. 2. Sequence of technical specification obtaining.

Besides varieties of BR types may also be isolated accompanying processes, which include the conservation and reconservation, recycling, industrialization, etc. [4].

Thus, the algorithm of updating the technical specification is the following:

1. The Contractor sends Customer the form of survey (profile).

2. The Customer, in conjunction with the Contractor completes the form, using the database for the three levels of features, defines the purpose of the work production (functional requirements), structural elements that require reorganization, organizational and technological production processes.

3. Then Contractor makes the comparison of standards model (S1-S8) with this obtained model of BR [5].

4. The Contractor determines the percentage of the matches the selected parameters to the results obtained through the three levels. Get the chain - modules for each type of BR that for further design recorded in the database of new information model for further processes [6].

5. Modules of the results (the recruitment process for each type of BR involved in the facility) should be agree with the Customer. [7] 


\section{References}

1. A.A. Volkov, S.N. Shulghenko, A.I. Shirokov, E.N Kulikova, Vestnik MGSU, 6 (2011)

2. A.A. Volkov, Stroitelnie materiali, oborydovanie, tehnologii XXI veka, 7 (2001)

3. O.N.Kuzina, V.O. Chulkov, R.R.Kazaryan, PGS, 11 (2009)

4. O.N.Kuzina, V.O. Chulkov, Sbornik trudov Stroitelstvo - formirovanie sredi jiznedeiatelnosti, 23, 67-72 (2009)

5. V.O. Chulkov, Pereystroistvo. Organizacionno-antropotehnicheskaia nadejnost stroitelstva (SVR-ARGUS, 2005)

6. K.A. Shreyber, Variantnoe proektirovanie pri reconstrukcii jilih zdanii, Seria Zhilishche - 2000, (Stroyizdat, Moscow, 1991)

7. O.N.Kuzina, V.O. Chulkov, PGS, 11 (2009)

8. 17. V.V Okrepilov, V.L. Makarov, A.R. Bakhtizin, S.N Kuzmina, Economy of Region, 2, 301-313 (2015)

9. V.L. Kvint, V.V Okrepilov, Herald of the Russian Academy of Sciences, 84(3), 188200 (2014)

10. V.V Okrepilov, V.N. Krutikov, G.I. El'kin, Measurement Techniques, 57(2),109-116 (2014)

11. S. Rutešić, J. Ćetković, M. Žarcković, M. Knežević, N. Vatin, Procedia Engineering, 117 (1), 905-915 (2015)

12. S. Rutešić, J. Ćetković, M. Knežević, M. Žarcković, N. Vatin, Procedia Engineering, 117(1), 642-650 (2015)

13. M. Jocovic, B. Melovic, N. Vatin, V. Murgul, Applied Mechanics and Materials, 678, 644-647 (2014)

14. G. Radovic, V. Murgul, N. Vatin, Applied Mechanics and Materials, 641-642, 634638 (2014)

15. M. Penića, S. Golovina, V. Murgul, Procedia Engineering, 117, 883-890 (2015) 